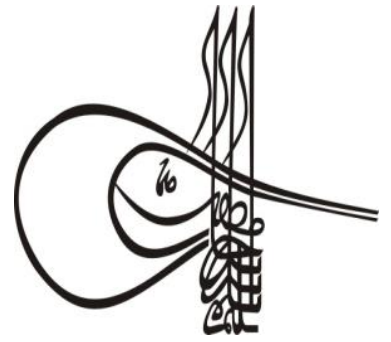

Received/Geliș: 10.11.2018
Turkígh Studies

\section{Information Technologies and} Applied Sciences

Volume 14 Issue 2, 2019, p. 213-226

DOI: 10.29228/TurkishStudies.22356

ISSN: 2667-5633

Skopje/MACEDONIA-Ankara/TURKEY

Research Article / Araştırma Makalesi

Article Info/Makale Bilgisi

$\checkmark$ Accepted/Kabul: 10.06 .2019

Go Report Dates/Rapor Tarihleri: Referee 1 (02.04.2019)-Referee 2 (26.12.2018)

This article was checked by iThenticate.

\title{
Y KUŞAĞI ÖĞRETMEN ADAYLARI VE SOSYAL MEDYA*
}

\author{
Seda GÜNDÜZALP $P^{* *}$ - Gönül ŞENER ${ }^{* * *}$
}

\begin{abstract}
ÖZET
Teknoloji çağının getirdikleriyle sosyal medyayla iç içe olan y kuşağın bu yöndeki özelliklerinin tespit edilmesinin, çalışma hayatında verimliliğe, etkililiğe ve üretkenliğe yön verme anlamında faydalı olacağı düşünülmektedir. Bu çalışmada birkaç yıl içinde meslek hayatına başlaması muhtemel olan öğretmen adaylarının Y kuşağı olmalarından doğan karakteristiklerinin belirlenmesi ve günlük hayatın bir parçası haline gelen sosyal medya kullanımının mesleğe etkilerini öngörmek amaçlanmıştır. Bu amaç doğrultusunda araştırma nitel desende tasarlanmıştır. Araştırmanın çalışma grubunu pedagojik formasyon programına kayıtlı öğretmen adaylarından oluşan 65 kişi oluşturmuştur. Araştırma verileri yarı yapılandırılmış görüşme formu ile elde edilmiştir. Araştırma verilerinin çözümlenmesinde nitel araştırmalarda sıklıkla kullanılan içerik analizi yöntemi tercih edilmiştir. Araştırma sonucunda; Y kuşağında yer alan öğretmen adayları öğretmen olarak atandıklarında kişisel önceliklerini; kendilerini gerçekleştirmek, kişisel gelişimini sağlamak, etkili iletişim becerilerini kazanmak, eşitlik ve adalet, ailem, düzen, lider olmak, sorumluluk bilinci, sevgi ve saygı, maddi güç, saygınlık kazanmak ve yardımlaşma olarak sıralamışlardır. Bu öğretmen adayları olumsuz olarak sosyal medyanın sıklıkla zaman çalıcı bir uygulama olduğunu belirtmişlerdir. Olumlu olarak ise kendini güncellemek, bilgiye ulaşmak ve etkili iletişimin yolu olarak tanımlamışlardır. Hayatımızda çok fazla yer alan sosyal medyanın öğretmenler açısından hem olumlu hem de olumsuz yanları mevcuttur. Y kuşağı olarak adlandırılan öğretmen adaylarının sosyal medyanın
\end{abstract}

\footnotetext{
* Bu makale “13. Uluslararası Eğitim Yönetimi Kongresi”nde sözlü bildiri olarak sunulmuştur.

** ID Dr. Öğr. Üyesi, Munzur Üniversitesi Pertek Sakine Genç MYO, E-posta: sedagunduzalp@munzur.edu.tr 
olumlu taraflarını kullanması, olumsuz taraflarını ise meslek hayatının gerisinde tutması önerilebilir. Ayrıca sosyal medyayı kişisel ve mesleki önceliklerine uygun olarak kullanması başarılarını arttırıcı bir unsur olarak görülebilir.

Anahtar Kelimeler: Y kuşağı, öğretmen adayı, sosyal medya

\title{
GENERATION Y CANDIDATE TEACHERS AND SOCIAL MEDIA
}

\begin{abstract}
The implications of technology era intertwined with the social media generation y to determine the characteristics of working life, productivity, would be helpful in terms of giving direction to the effectiveness and productivity are considered. In this study to determine the characteristics of being born $\mathrm{Y}$ generation of teachers who will start his career in a few years, aimed use of social media has become a part of daily life to predict the effects of the profession. Content analysis method which is frequently used in qualitative research is preferred in analyzing research data. The study group of the study consisted of 65 people composed of candidate teachers enrolled in the formation program. The research data were obtained by semi-structured interview form. As a result of the research; Candidates teacher in generation $\mathrm{Y}$ have personal priorities when appointed as teachers; perform myself, to provide personal development, to gain effective communication skills, equality and justice, family, order, being a leader, responsibility awareness, love and respect, material power, to gain prestige and help as listed. These candidate teachers stated that social media is often a time-consuming practice. On the positive side, they defined themselves as a way of updating themselves, accessing information and communicating effectively. Social media, which has a lot in our lives, have both positive and negative aspects for teachers. It can be suggested that candidate teachers called the $\mathrm{Y}$ generation use the positive aspects of social media and keep their negative side behind their professional life. In addition, the use of social media in accordance with personal and professional priorities can be seen as an increasing element of success.
\end{abstract}

\section{STRUCTURED ABSTRACT}

In today's social structure, where big changes are experienced, and the borders are eliminated with the effect of developing technology and the transformation of the world into a small village; therefore differences in beliefs, personal expectations, attitudes and behaviors were also clearly begin to observe in the business world. The similar characteristics of the people who were born in the same years have increased the interest of researchers on this subject. As a result of the researches, it is seen that generation $\mathrm{Y}$, which constitutes a large part of the working life and who will have a managerial position in the coming years, follows a very different profile from the previous generations with the effect of both technology and globalization (Kelgökmen İliç ve Yalçın, 2017).

Turkish Studies - Information Technologies and Applied Sciences Volume 14 Issue 3, 2019 
Generation $\mathrm{Y}$ affects the Internet generation or global generation, the net generation most and directly from information technologies and/or electronic communications (e-communication) (Yessil ve Fidan, 2017). Many researchers also suggest that generation $Y$ is a new wave of transformation in social and business life. This generation believes that they can achieve everything and that they are transformative. Unlike their parents, they grew up in an environment surrounded by contemporary technologies and consumer society (Islam vd., 2011). The characteristics of Generation Y are listed below (Williamson \& Meyer-Looze, 2017):

$>$ They are highly educated and attribute their success to education,

$>$ They use technology very easily and expect easy access to technology in the workplace,

$>$ They tend to be creative, innovative and confident,

$>$ They want to make a difference and make a positive contribution to social change,

$>$ They want to connect, update, be involved and participate in business life,

> They want to establish good relations with colleagues and supervisors,

> They want to look for opportunities for growth in business programs, challenging jobs and assignments and flexibility,

$>$ They have the ability to cooperate, fearless of accountability.

It is thought that determining the characteristics of $\mathrm{Y}$ generation individuals who are intertwined with social media with the implications of the age of technology will be beneficial in terms of directing productivity, efficiency and productivity in working life. The aim of this study is to determine the characteristics of candidate teachers who are likely to start their professional life within a few years and to predict the effects of social media usage which has become a part of daily life. For this purpose, the research was designed in qualitative design. The study group consisted of 65 candidate teachers enrolled in the pedagogical formation program. The data were obtained through a semi-structured interview form. In the development of the interview form used in the study, first of all the literature was examined in parallel with the aim of the research. As a result of the survey, research questions were created, and expert opinion was taken by two academicians who experts in their fields in order are to ensure the content validity. In order to test the comprehensibility of the revised form in line with the recommendations of the expert opinion, were applicated to ten candidate teachers. Following this process, the interview forms were examined, and the applicability of the form was determined. The questions prepared to determine the general views of candidate teachers were asked during the interviews conducted by the researcher. Teachers' responses were noted and recorded. The data obtained by recording the views of the teachers one by one were accepted as the main data source of the research. The questions in the interview form are given below:

1. When I am appointed as a teacher;

a) my professional priorities

b) my personal priorities are

2. Social media is for me.

Turkish Studies - Information Technologies and Applied Sciences Volume 14 Issue 3, 2019 
3. Explain the positive and negative aspects of social media use to the teaching profession.

Content analysis method was used to analyze, interpret and interpret the qualitative data obtained from the participants and to obtain objective and systematic results from certain characters defined in the text (Stone vd., 1966; GAO, 1996). In the analysis of the opinions of the candidate teachers, firstly the themes were formed by grouping according to the similarity of the answers given, then the opinions were placed on the themes that they thought were related. Frequency values of each theme and vision were determined and presented through the figures. In addition, direct quotations and participant views were provided to illustrate each theme. In order to measure the reliability of the research, it was tried to determine whether the participants represented the theme they were placed based on their opinions by using expert opinion. According to Miles and Heberman (1994), in the qualitative studies, it is stated that credibility will be ensured when the agreement between the experts and researchers is $90 \%$ or more. Accordingly, the consulted expert placed only eighteen statements in a category different from the researchers. After this calculation, the reliability of the research; $\mathrm{P}=510 /(510+18) \mathrm{X} 100=\% 96$ it was found as.

As a result of the research; candidate teachers in the $\mathrm{Y}$ generation when they are appointed as teacher will have personal priorities following ; to realize themselves, to provide personal development, to gain effective communication skills, equality and justice, my family, order, to be a leader, responsibility awareness, love and respect, material strength, to gain respect and help. These candidate teachers stated that social media is a time-consuming practice. On the other hand, they defined themselves as a way of updating themselves, accessing information and effective communication. Social media, which has a lot in our lives, has both positive and negative aspects for teachers. It can be suggested that candidate teachers, called Y generation, should use the positive sides of social media and keep the negative sides behind their professional life. In addition, using social media in accordance with personal and professional priorities can be seen as an increase in their success.

Keywords: Generation Y, candidate teachers, social media.

\section{Giriş}

Tarihsel süreç içerisinde birbirlerine yakın zamanlarda dünyaya gelen bireylerin benzer özellikler taşıması kuşak kavramını ortaya çıkarmıştır (İşçimen, 2012). Kuşak kavramı "ebeveynlerin ve çocuklarının doğumları arasındaki ortalama zaman aralığı" olarak ifade edilmektedir (McCrindle \& Wolfinger, 2010). Diğer bir tanımda kuşak, belirli bir tarih aralığında doğan, belirli bir yaş aralığını paylaşan ve kritik gelişim aşamalarında belirli olayları yaşayan kişilerden oluşan bir grup olarak tanımlanmaktadır (Kupperschmidt, 2000). Kuşak çalışmaları ile ilgili bilimsel araştırmaların öncüsü olarak kabul edilen Auguste Comte, çalışmalarını 1830-1840 yılları arasında sürdürmüştür. Comte (1974), kuşakla ilgili değişikliklerin tarihi süreç içerisinde dinamik kuvvetler olduğunu belirterek, toplumsal gelişimin ise ancak bir kuşağın sonraki kuşağa aktaracağı birikimler ile gerçekleşeceğini ileri sürmüştür. Toplumsal gelişim ve değişimde kuşakların sahip olduğu özelliklerinin ve aralarındaki ilişkinin önemi büyüktür.

Bugünün hem toplumsal yapısına hem de işgücüne bakıldığında beş kuşağın bireylerinden oluşan bir yapıdan söz edilebilir. Bu kuşaklar üzerinde: 1925-1945 arasında doğanlar için Sessiz Kuşak; 
1946-1964 doğumlular için Bebek Patlaması, Boomers; 1965-1980 arasında doğanlar için X Kuşağı, Gen X; 1980-2000 arasında doğanlar için Y kuşağı, Gen Me, Gen Y; 1980-2000 arasında doğanlar için Milenyum, nGen ve İGen; 2000 ve sonrası doğanlar için Z Kuşağı tanımlaması yapılmaktadır (Twenge, Campell, Hoffman \& Lance, 2010). Yapılan araştırmalar kuşak farklılıklarının nedenini kişisel özellikler, davranışlar ve tutumlar olarak göstermiştir (Thornton \& Young- DeMarco, 2001; Trzesniewski, Donnellan, \& Robins, 2008; Twenge, Zhang \& Im, 2004; Wells \& Twenge, 2005). Her kuşağın kendine özgü belirgin özellikleri tanımlanabilir. Bu özellikler toplumsal yapı, çevresel ve tarihsel koşullar, kültür, sosyo-ekonomik düzey, teknolojik gelişmeler gibi birçok faktörün etkisi altında ortaya çıkmaktadır.

Savaş kuşağı olarak da adlandırılan sessiz kuşağa baktığımızda günümüz çalışma yaşamında çalışanları en yaşlı gruptur, iş dünyasında daha az sayıda yer almalarının sebebi, çoğunun yaşı gereğince emekliye ayrılmış olmasıdır (Patalano, 2008). II. Dünya Savaşı sonrası dünya genelinde oluşan nüfus artışı sebebiyle bebek patlaması olarak adlandırılan yeni bir kuşak ortaya çıkmıştır. Bu kuşak çalışma hayatına sanayi işçisi olarak başlamış, günümüzde bilgi işçilerine dönüşmüştür. Geçmiş kuşakların görmediği büyük bir değişim görmüş ve her evrede yeni yetenekler kazanmak zorunda kalmıştır (Gündüz ve Pekçetaş, 2018). Teknolojik devrime denk gelen X kuşağı üyeleri ise zorunlu olarak teknolojiyi kullanmaya başlamışlardır. Bu kuşak toplumsal sorunlara karşı duyarlı, iş motivasyonları yüksek ve otoriteye saygılıdırlar. Kadınların iş gücüne katılmaya başlaması ve az çocuk sahibi olmak istemeleri bu kuşak için önemli değerlerdir (Mengi, 2009). Günümüz meslek alanlarında mesleğe yeni başlamış ve başlayacak olan gruba karşılık gelen Y kuşağının çalışma ortamından beklentileri, gösterecekleri performans, iletişim düzeyleri, yeterlilikleri gibi özelliklerinin bir önceki kuşak olan X kuşağından farklı olduğu görülmektedir. Y kuşağı üyelerini tanımlayan en etkin faktörün teknolojiye olan bağl11ıkları olduğunu söylemek mümkündür. Y kuşağı olarak tanımlanan bireyler teknoloji ile büyümüş ve yaşamlarının her anında teknolojiyi kullanır durumda olmuşlardır. Bu kuşak işlerini kolaylaştırma konusunda teknolojinin tüm imkânlarından yararlanmayı bilmişlerdir. Zamanlarının büyük çoğunluğunu medya ve iletişim teknolojileri ile etkileşim halinde geçirdikleri bilinen Y kuşağ için teknoloji hayatlarının merkezinde önemli bir simgedir (Yaşa ve Bozyiğit, 2012).

Gelişen teknolojinin etkisi ve dünyanın küçük bir köye dönüşmesi ile büyük değişimlerin yaşandığı ve sınırların ortadan kalktığı günümüzde toplumsal yapıda, inançlarda, kişisel beklentilerde, tutum ve davranışlarda oluşan farklılıklar iş dünyasında da açık bir şekilde gözlenmiştir. Yakın dönemlerde dünyaya gelen insanların benzer karakteristiklere sahip olması araştırmacıların bu konu hakkında ilgilerinin artmasına sebep olmuştur. Yapılan araştırmalar sonucunda çalışma yaşamının büyük bir bölümünü oluşturan ve önümüzdeki yıllar içerisinde yönetici konumuna sahip olacak olan Y kuşağı hem teknolojinin hem de küreselleşmenin etkisiyle kendinden önce gelen kuşaklardan çok farkl1 bir profil izlemektedir (Kelgökmen İliç ve Yalçın, 2017). Y kuşağ internet kuşağı veya küresel kuşak, net kuşağı bilişim teknolojileri ve/veya elektronik iletişimden (e-iletişim) en çok ve doğrudan etkilemektedir (Yeşil ve Fidan, 2017). Yine birçok araştırmacı Y kuşağının sosyal ve iş yaşamında yeni bir dönüşüm dalgası olduğunu ileri sürmektedir. Bu kuşak her şeyi elde edebileceğine ve kendilerinin dönüşümcü olduklarına inanmaktadırlar. Çünkü onlar anne ve babalarından farklı olarak çağdaş teknolojiler ve tüketim toplumu tarafindan çevrelenmiş bir çevrede yetişmişlerdir (Islam vd., 2011). Y kuşağının özellikleri aşağıda sıralanmıştır (Williamson \& Meyer-Looze, 2017):

$>$ Yüksek eğitimlidirler, başarılarını eğitime atfederler,

$>$ Teknolojiyi çok rahat kullanır ve işyerinde teknolojiye kolay erişim olmasını beklerler,

$>$ Yaratıc1, yenilikçi ve özgüvenli olma eğilimindedirler,

$>$ Fark yaratmak ve sosyal değişime pozitif katkıda bulunmak isterler,

$>$ İş yaşamında bağlanmak, güncellemek, dahil edilmek ve çalışmalara katılmak isterler,

$>$ İş arkadaşlarıyla ve denetçilerle iyi ilişkiler kurmak isterler,

$>$ İş programlarında büyüme, zorlu iş ve ödevleri ve esneklik firsatlarını aramak isterler,

Turkish Studies - Information Technologies and Applied Sciences

Volume 14 Issue 3, 2019 
İşbirliği becerilerine sahiptirler, hesap verebilme konusunda korkusuzdurlar.

Çeşitli mesleklerden bilim insanları, Y kuşağının önceki nesillere göre farklı değerlere ve ihtiyaçlara sahip olduğuna işaret etmişlerdir. Öğretmenler, Y kuşağının özellikleri hakkında bu yazarların görüşlerinden faydalanabilirler. Bu görüşler daha çok dijitalleşme ve bireylerin görsel yaşamlarıyla ilgilidir. Görüşler ayrıca kurallara ve dürüstlüğe karşı tutumları, saygının yeniden tanımlanmasını, okumaya olan ilginin azalmasını ve farklı olma arzusunu da içine almaktadır. $\mathrm{Bu}$ özelliklerin farkında olarak, öğretmenlerinin iki şeyi yapmalarını gerektirmektedir: (1) Y kuşağının doğasını anlamak ve (2) akademik ihtiyaçlarına cevap veren öğretim stratejilerini benimsemek (Reilly, 2012).

Y Kuşağı, başarıya, dünyayı daha iyi bir şekilde değiştirmeye, etkileşim ve yenilikçi olan iletişim ve sunum stillerine çok bağlı olduğundan, bu kuşağın öğretmenleri güçlü eğitimciler olacaktır. Okul yöneticilerinin, bu güçlü eğitimcileri destekleme ve kuruma bağl1lıkları arttırma konusunda ortam oluşturmak için önemli adımlar atmaları gerekmektedir. Y Kuşă̆ı'nda öğretmenin görevleri; gelecek nesil öğrencilerine anlamlı hayatlar sürmeleri ve toplumsal ilerlemeyle birlikte olumlu beceriler kazanması konusunda rehber olmaktır (Behrstock \& Clifford, 2009).

Özellikle teknoloji çağının getirdikleriyle sosyal medyayla iç içe olan Y kuşağının özelliklerinin tespit edilmesinin, çalışma hayatında verimliliğe, etkililiğe ve üretkenliğe yön verme anlamında faydalı olacağı düşünülmektedir. Bu çalışmada birkaç yıl içinde meslek hayatına başlayacak olan öğretmen adaylarının Y kuşağı olmalarından doğan karakteristiklerinin belirlenmesi, günlük hayatın bir parçası haline gelen sosyal medya kullanımının mesleğe etkilerini öngörmeyi amaçlanmıştır.

\section{Yöntem}

$\mathrm{Bu}$ araştırma, nitel paradigma içerisinde değerlendirilen olgubilim "fenomenoloji” deseni ile şekillendirilmiştir. Olgubilim deseni, görebildiğimiz ancak derinlemesine ve ayrıntılı bir anlayışa sahip olmadığımız olgular üzerinde düşünmemizi sağlar. Olgubilim farkında olduğumuz ancak tam olarak anlamını kavrayamadığımız olguları araştırmamıza yardımcı olur (Yıldırım \& Şimşek, 2005).

\section{Çalışma Grubu}

Araştırmada çalışma grubunun belirlenmesinde olasıllk temelli örnekleme yöntemleri içinde yer alan amaçlı örnekleme yöntemi kullanılmıştır. Amaçlı (yargısal) örneklemede araştırmacı kimlerin seçileceği konusunda kendi yargısını kullanır ve araştırmanın amacına en uygun olanları örnekleme alır (Balc1, 2005). Burada araştırmacı neyin bilinmesi gerektiğine karar verir ve bilgi veya deneyim sayesinde araştıma sorusunun karşıllı̆ını bulabilmek için en iyi bilgi kaynağı olabilecek, bilgiyi sağlayabilecek ve vermeye istekli insanları bulmak için yola çıar (Bernard 2002; Lewis \& Sheppard 2006; Tango, 2007). Bu doğrultuda araştırmanın amacını gerçekleştireceği düşünüldüğü için 2017-2018 eğitim-öğretim yılında Fırat Üniversitesi Pedagojik Formasyon programında kayıtlı öğretmen adaylarından oluşan 65 kişi çalışma grubu olarak belirlenmiş̧ir.

Tablo 1: Çalışma Grubunun Demografik Özelliklerine İlişkin Frekans ve Yüzde Dağılımları

\begin{tabular}{|c|c|c|c|c|c|c|c|c|c|c|}
\hline Değişkenler & & & & & & & & & & Toplam \\
\hline \multirow{3}{*}{ Cinsiyet } & & Kadın & Erkek & & & & & & & \\
\hline & $\mathrm{N}$ & 48 & 17 & & & & & & & 65 \\
\hline & $\%$ & 73.85 & 26.15 & & & & & & & 100 \\
\hline \multirow{3}{*}{ Bölüm } & & Tarih & Coğrafya & TDE & Felsefe & $\begin{array}{c}\text { Kamu } \\
\text { Yönetimi }\end{array}$ & $\begin{array}{c}\text { Yaşayan } \\
\text { Diller }\end{array}$ & Sağlık & Gazetecilik & - \\
\hline & $\mathrm{N}$ & 15 & 12 & 12 & 9 & 8 & 4 & 3 & 2 & 65 \\
\hline & $\%$ & 23.08 & 18.46 & 18.46 & 13.84 & 12.30 & 6.16 & 4.62 & 3.08 & 100 \\
\hline \multirow{3}{*}{ Yaş } & & $20-25$ & $26-30$ & $31+.$. & & & & & & - \\
\hline & $\mathrm{N}$ & 54 & 4 & 7 & & & & & & 65 \\
\hline & $\%$ & 83.08 & 6.16 & 10.76 & & & & & & 100 \\
\hline
\end{tabular}




\section{Veri Toplama Aracı}

Çalışmada kullanılan görüşme formunun geliştirilmesinde öncelikle araştırmanın amacına paralel olarak alan yazın incelenmiştir. Yapılan tarama sonucunda araştırma soruları oluşturulmuş ve kapsam geçerliğini sağlamak adına alanında uzman iki akademisyen tarafından uzman görüşü alınmıştır. Uzman görüşünün önerileri doğrultusunda yeniden düzenlenen formun anlaşllabilirliğini test etmek amacıyla on öğretmen adayına pilot uygulama yapılmıştır. Bu işlemin ardından uygulanan görüşme formlan incelenmiş ve inceleme sonunda formun uygulanabilirliğine karar verilmiştir. Öğretmen adaylarının genel görüşlerini belirlemeye yönelik olarak hazırlanan sorular araştırmacı tarafından yapılan görüşmeler sırasında sorulmuştur. Öğretmenlerin verdiği yanıtlar not alınarak kayıt altına almıştır. Öğretmenlerinin görüşlerinin birebir kayıt altına alınmasıyla elde edilen veriler araştırmanın temel veri kaynağı olarak kabul edilmiştir. Görüşme formunda yer alan sorulara aşağıda yer verilmiştir:

1. Öğretmen olarak atandığımda;

a) mesleki önceliklerim ............................................ olur.

b) kişisel önceliklerim.................................................olur.

2. Sosyal medya benim için ................................................................................. dir.

3. Sosyal medya kullanımının, öğretmenlik mesleğine olumlu ve olumsuz yanları size göre nelerdir açıklayınız.

\section{Verilerin Analizi}

Araştırmada katılımcılardan elde edilen nitel verileri çözümlemek, anlamlandırmak ve yorumlamak, metin içinde tanımlanan belirli karakterlerden tarafsız ve sistematik sonuçlar elde etmek amacıyla içerik analizi yöntemi kullanılmıştır (Stone vd., 1966; GAO, 1996). Yazıl1, sözlü veya görsel iletişim mesajlarını analiz etme yöntemi olan içerik analizi; metin veya metinlerdeki büyük miktardaki veriyi organize edilmiş anlamlı bir sonuç haline sistematik olarak dönüştürmektir (Cole, 1998; Erlingsson, \& Brysiewicz, 2017). Bu analizde temelde yapılan işlem, birbirine benzeyen verileri belirli kavramlar ve temalar çerçevesinde bir araya getirmek ve bunu okuyucunun anlayabileceği bir biçimde organize ederek yorumlamaktır (Yıldırım \& Şimşek, 2005).

Araştırmada her bir öğretmen ile yapılan görüşme sonucunda elde edilen formların incelemesi sonunda öğretmen adaylarından toplanan 65 görüşme formunun tamamı geçerli kabul edilmiştir. bu formlar aracılığıyla elde edilen veriler üzerinde çözümlemeler yapılmıştır. 65 form bir Word belgesinde oluşturulan tablo ile her birine sırayla sayı numarası verilerek, her bir soru için satır oluşturulmuş ve yanıtlar bu tabloya işlenmiştir. Daha sonra bilgisayar ortamında hazırlanan veriler, nitel veri analiz programı olan NVivo programı ile analiz edilmiştir. Öğretmen adaylarının görüşlerinin analizinde, öncelikle verilen yanıtların benzerliğine göre gruplandırmalar yapılarak temalar oluşturulmuş, ardından, görüşler ilişkili olduğu düşünüldügü temalara yerleştirilmiştir. Her bir temaya ve görüşe ait frekans değerleri belirlenerek, şekiller aracılığıyla sunulmuştur. Ayrıca, her bir temaya ilişkin örnek teşkil etmesi amacıyla doğrudan alıntılarla katılımcı görüşlerine yer verilmiştir. Araştırmanın güvenirliliğini ölçmek amacıyla, katılımcıların görüşlerinden yola çıkarak yerleştirildiği temayı temsil edip etmediğini uzman görüşüne başvurularak belirlenmeye çalışılmıştır. Uzman görüşleriyle birlikte, araştırmanın güvenilirliğini ölçmek için Miles ve Heberman'ın (1994) geliştirdiği aşağıdaki formül kullanılmıştır.

$$
\text { UzıaşmaYüzdesi }=\frac{\text { GörüşBirliği( } \mathrm{Na})}{\text { GörüşBirliği( } \mathrm{Na})+ \text { GörüşAyrılığı }} 100
$$

Miles ve Heberman'a (1994) göre nitel çalışmalarda, uzman ve araştırmacı değerlendirmeleri sonunda aralarındaki uyumun $\% 90$ ve üzeri olduğu durumlarda güvenirliğin sağlanmış olacağını ifade etmektedir. Buna göre görüşüne başvurulan uzman sadece on sekiz ifadeyi araştırmacılardan farklı bir 
kategoriye yerleştirmiştir. $\mathrm{Bu}$ hesaplamanın ardından araştırmanın güvenirliği; $\mathrm{P}=510 /(510+18) \mathrm{X} 100=\% 96$ olarak bulunmuştur.

\section{Bulgular}

Görüşme formu aracıllı̆ıyla elde edilen verilerin analizi sonucu ortaya çıkan bulgulardan ilk olarak Y kuşağında yer alan öğretmen adaylarının mesleki önceliklerine ilişkin görüşleri Şekil 1'de gösterilmiştir.
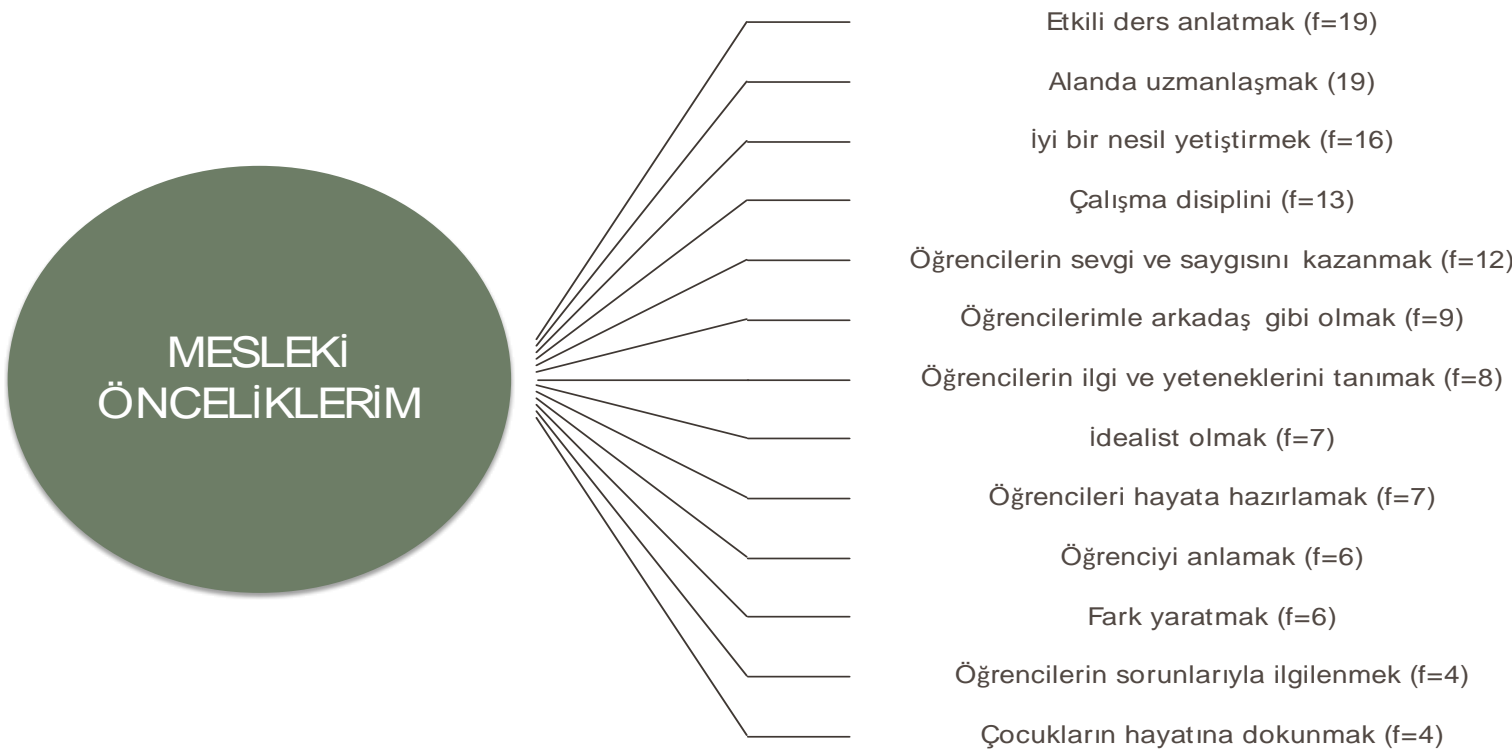

Şekil 1: Y kuşağında yer alan öğretmen adaylarının mesleki önceliklerine ilişkin görüşleri

Y kuşağında yer alan öğretmen adayları mesleki önceliklerini sıklıkla etkili ders anlatmak $(\mathrm{f}=19)$, alanda uzmanlaşmak ( $\mathrm{f}=19)$, iyi bir nesil yetiştirmek ( $\mathrm{f}=16)$, çalışma disiplini $(\mathrm{f}=13)$, öğrencilerin sevgi ve saygısını kazanmak ( $\mathrm{f}=12)$, öğrencilerimle arkadaş gibi olmak $(\mathrm{f}=9)$, öğrencilerin ilgi ve yeteneklerini tanımak ( $\mathrm{f}=8)$, idealist olmak $(\mathrm{f}=7)$, öğrencileri hayata hazırlamak $(\mathrm{f}=7)$, öğrenciyi anlamak $(f=6)$, fark yaratmak $(f=6)$, öğrencilerin sorunlarıyla ilgilenmek $(f=4)$ ve çocukların hayatına dokunmak ( $\mathrm{f}=4$ ) olarak sıralamışlardır. Y kuşağında yer alan öğretmen adaylarının kişisel önceliklerine ilişkin görüşleri Şekil 2'de gösterilmiştir.
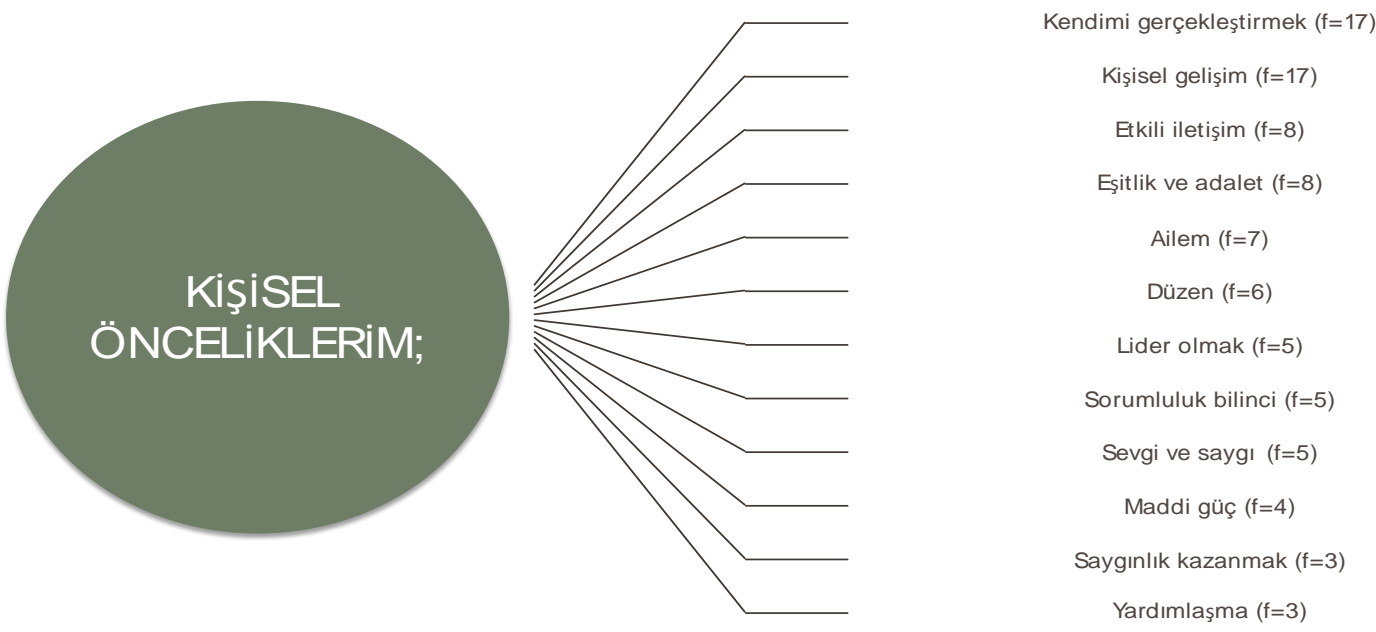

Şekil 2: Y kuşağında yer alan öğretmen adaylarının kişisel önceliklerine ilişkin görüşleri 
Y kuşağında yer alan öğretmen adayları kendini gerçekleştirmek $(\mathrm{f}=17)$, kişisel gelişim $(\mathrm{f}=17)$, etkili iletişim ( $(\mathrm{f}=8)$, eşitlik ve adalet $(\mathrm{f}=8)$, aile $(\mathrm{f}=7)$, düzen $(\mathrm{f}=6)$, lider olmak $(\mathrm{f}=5)$, sorumluluk bilinci $(f=5)$, sevgi ve saygı $(f=5)$, maddi güç $(f=4)$, saygınlık kazanmak $(f=3)$ ve yardımlaşmayı $(f=3)$ kişisel öncelikleri olarak değerlendirmişlerdir. Y kuşağında yer alan öğretmen adaylarının sosyal medya tanımlarına ilişkin bulgular Şekil 3'te gösterilmiştir.

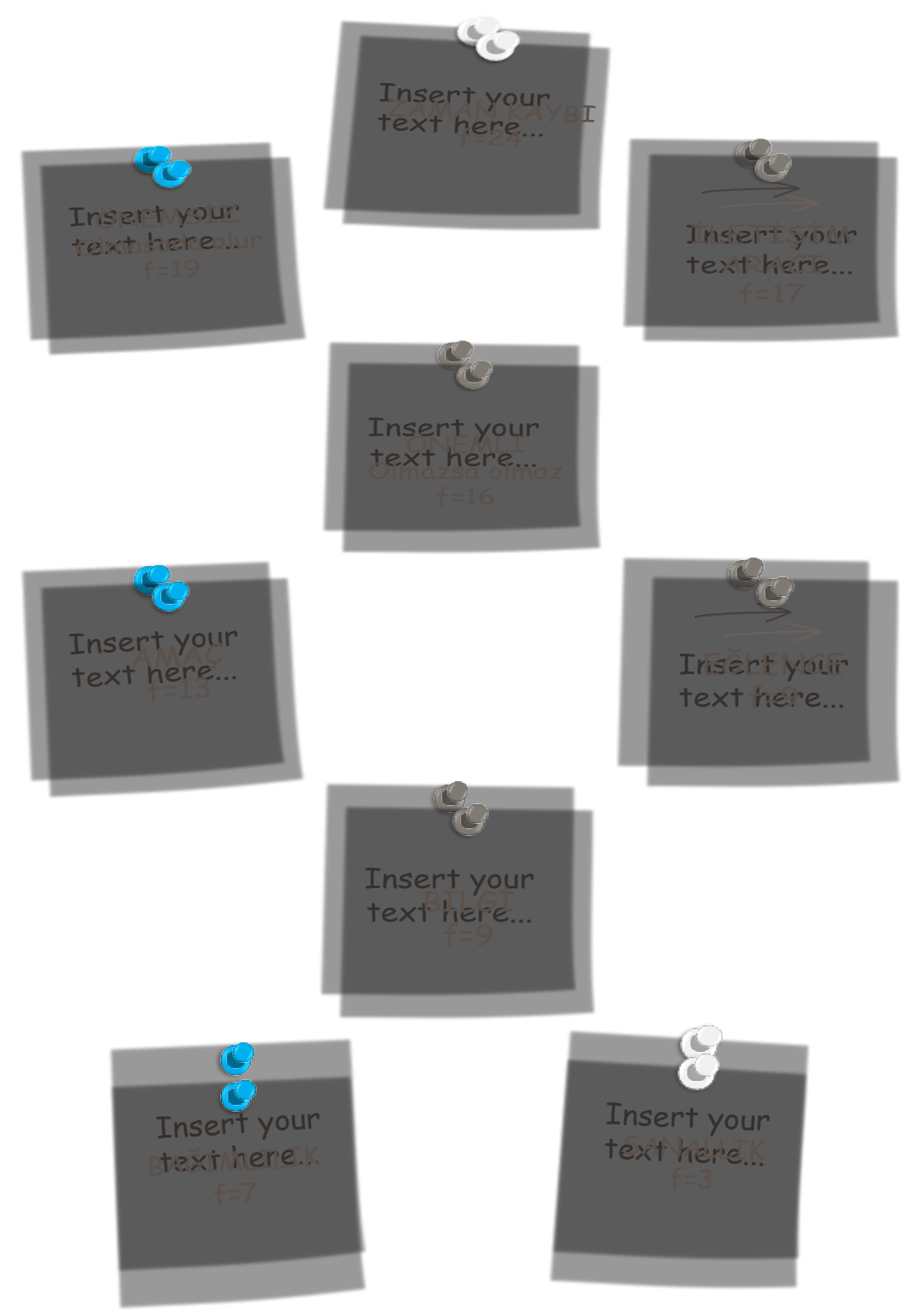

Şekil 3: Y kuşağında yer alan öğretmen adaylarının sosyal medya algıları

Günümüz insanı için en vazgeçilmez unsurlardan biri olan sosyal medyaya ilişkin Y kuşağı öğretmen adaylarının görüşleri incelendiğinde; öğretmen adayları sosyal medyayı sıklıkla zaman kayb1 $(\mathrm{f}=24)$ olarak görmüşlerdir. Bu görüşü sırasıyla olmasa da olur (önemsiz) ( $\mathrm{f}=19)$, iletişim aracı $(\mathrm{f}=17)$, olmazsa olmaz (önemli) ( $\mathrm{f}=16)$, amaç ( $\mathrm{f}=13$ ), eğlence ( $\mathrm{f}=9$ ), bilgi $(\mathrm{f}=9)$, bağımlılık $(\mathrm{f}=7)$, sanallık $(\mathrm{f}=3)$ izlemiştir. Sosyal medya kullanımının öğretmenlik mesleğine olumsuz yansımalarının sorgulandığı soruya ilişkin bulgular Şekil 4'te gösterilmiştir. 

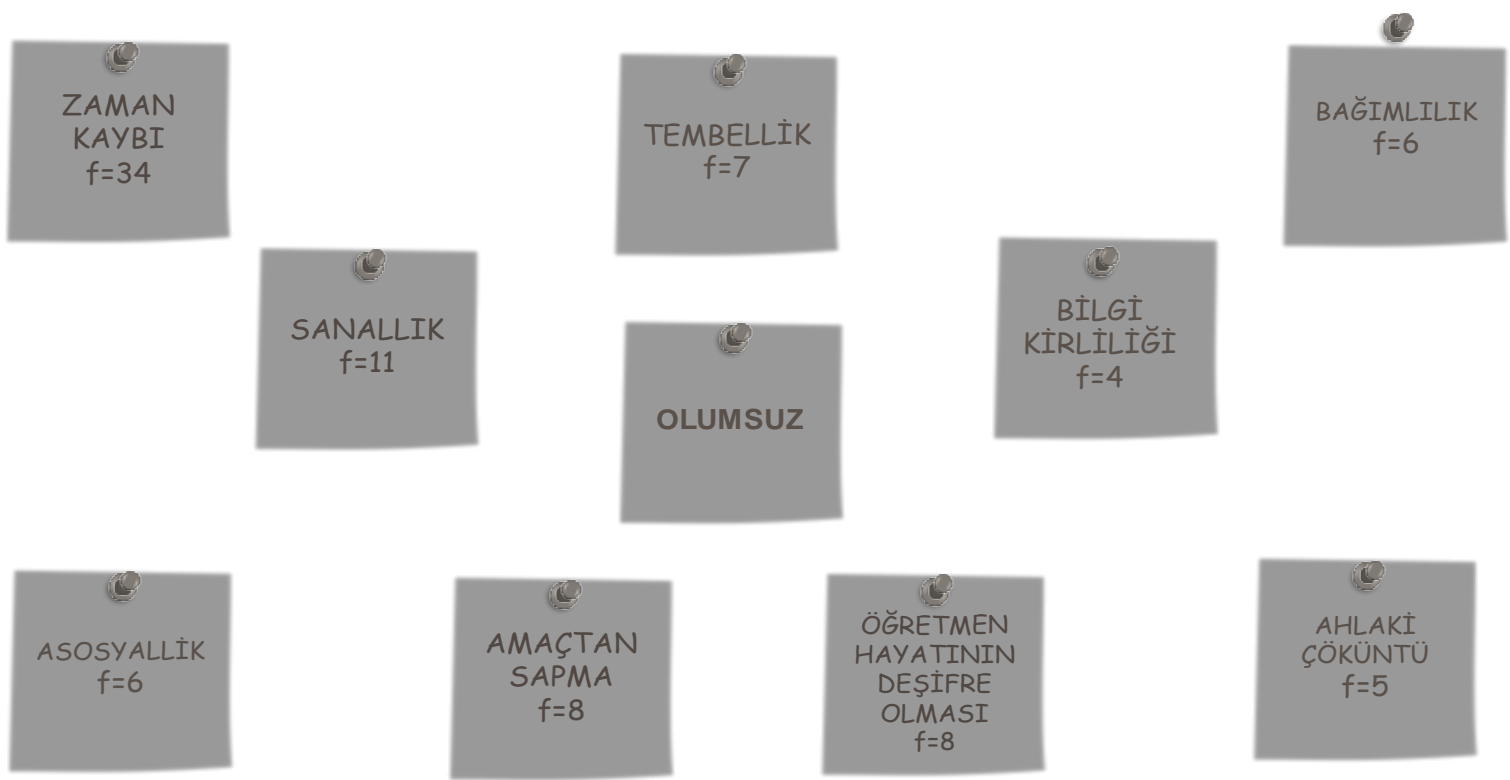

Şekil 4: Sosyal medya kullanımının, öğretmenlik mesleğine olumsuz yansımaları

Y kuşağında yer alan öğretmen adaylarının sosyal medya kullanımının öğretmenlik mesleğine olumsuz yansımalarına ilişkin görüşleri incelendiğinde; öğretmen adayları sıklıkla sosyal medyanın zaman kaybı $(\mathrm{f}=34)$ olduğu görüşünü ileri sürmüşlerdir. $\mathrm{Bu}$ görüşü sanallık (gerçek hayattan uzaklaşmak) ( $\mathrm{f}=11)$, amaçtan sapma $(\mathrm{f}=8)$, öğretmen hayatının deşifre olması $(\mathrm{f}=8)$, tembellik $(\mathrm{f}=7)$, bağımlılık ( $\mathrm{f}=6$ ), asosyallik ( $\mathrm{f}=6)$, ahlaki çöküntü $(\mathrm{f}=5)$, bilgi kirliliği $(\mathrm{f}=4)$ görüşleri izlemiştir. Sosyal medya kullanımının öğretmenlik mesleğine olumlu yansımalarının sorgulandığı soruya ilişkin bulgular Şekil 5'te gösterilmiştir.
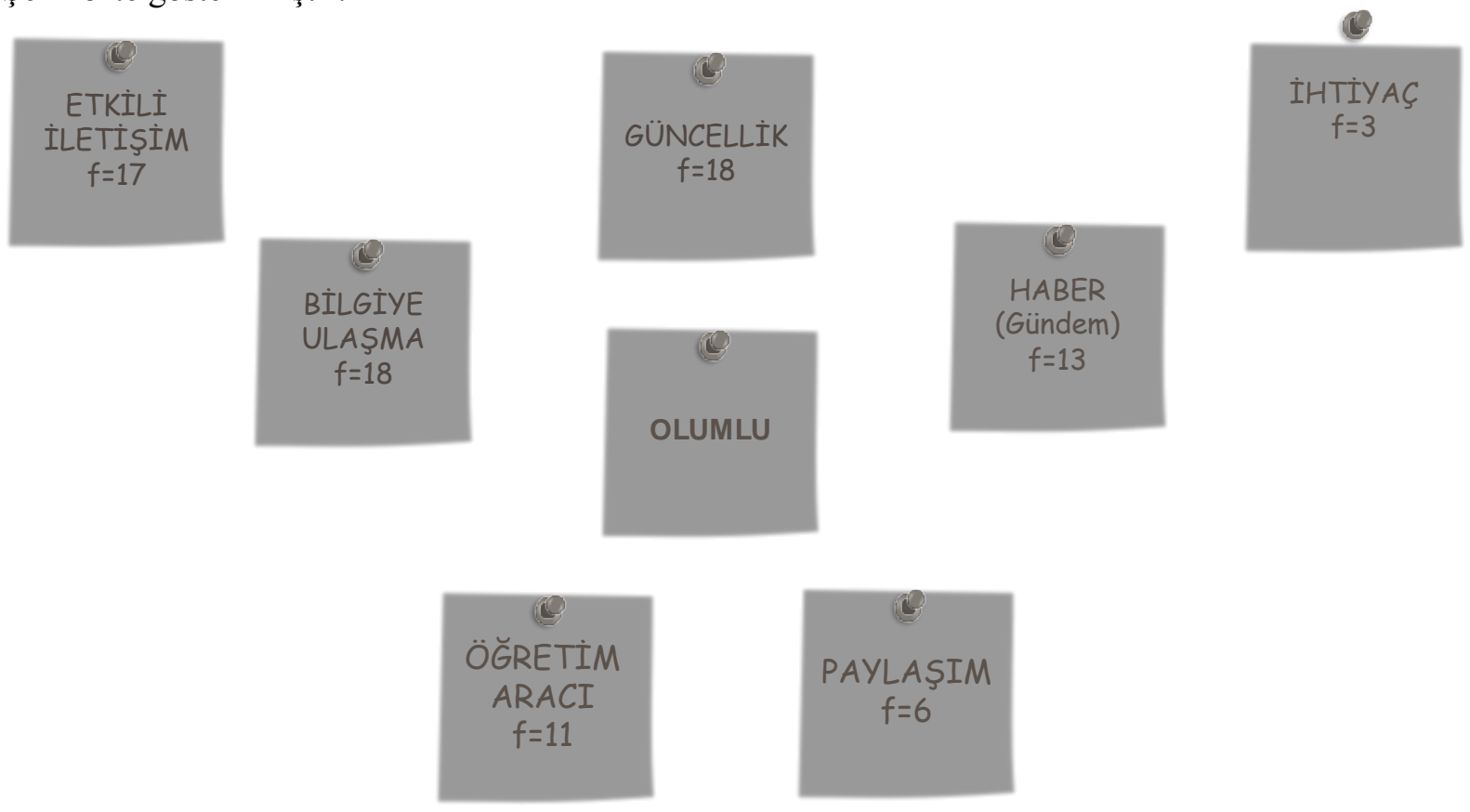

Şekil 5: Sosyal medya kullanımının, öğretmenlik mesleğine olumlu yansımaları

Turkish Studies - Information Technologies and Applied Sciences Volume 14 Issue 3, 2019 
Y kuşağında yer alan öğretmen adaylarının sosyal medya kullanımının öğretmenlik mesleğine olumlu yansımalarına ilişkin görüşleri incelendiğinde; öğretmen adayları sıklıkla güncellik $(\mathrm{f}=18)$ ve bilgiye ulaşma ( $\mathrm{f}=18)$ görüşlerini ileri sürmüşlerdir. Bu görüşleri etkili iletişim $(\mathrm{f}=17)$, haber alma $(\mathrm{f}=13)$, ögretim aracı $(\mathrm{f}=11)$, paylaşım $(\mathrm{f}=6)$ ve ihtiyaç $(\mathrm{f}=3)$ izlemiştir.

\section{Sonuç ve Tartışma}

Çalışmada yapılan analizler sonucunda elde edilen bulgular doğrultusunda öğretmen adayları öğretmen olarak atandıklarında mesleki önceliklerini etkili ders anlatmak, alanda uzmanlaşmak, iyi bir nesil yetiştirmek, çalışma disiplini içinde olmak, öğrencilerin sevgi ve saygısını kazanmak, öğrencileriyle arkadaş gibi olmak, öğrencilerin ilgi ve yeteneklerini tanımak, idealist olmak, öğrencileri hayata hazırlamak, öğrenciyi anlamak, fark yaratmak, öğrencilerin sorunlarıyla ilgilenmek ve çocukların hayatına dokunmak olarak sıralamışlardır. Bu bulguyla birlikte $Y$ kuşağı öğretmen adaylarının öğretmen olma durumlarında mesleki anlamda kendilerinden beklenen birçok görevi yerine getirmeyi önceledikleri görülmektedir. Akdemir ve Konakay (2014)'ın Y kuşağının girişimcilik ruhuna sahip, kendi eğitim alanıyla ilgili çalışma isteği taşımakta olduğu sonucuna ulaşması elde edilen sonucu destekler nitelikte olmuştur. Ayrıca etkili ders anlatmayı ve alanda uzmanlaşmayı mesleki anlamda önceleyen öğretmen adayları bunun yanında, öğrenciyi anlamak, tanımak ve onları hayata hazırlamak gibi öğrenciyi merkeze alan ifadeleri de oldukça sık kullandıkları bulgusu araştırma sonuçlarından biri olmuştur. Çakmak ve Kayabaşı (2017)'nin yaptığı çalışmasında öğretmen adaylarının öğretmenlik mesleğini seçme nedenleri arasında; eğitim sisteminin iyi öğretmenlere ihtiyacı olması, gelecek kuşakları eğitme ve öğretmeyi sevme olarak ortaya çıkması her iki çalışmada da öğretmen adaylarının mesleki önceliklerinin paralellik gösterdiğini söylemek mümkündür. Bunun dışında araştırmada yapılan analizler sonucunda formasyon eğitimi alan öğretmen adaylarının öğretmenlik mesleğine ilişkin olumlu görüşlerinin olduğu görülmektedir. Benzer şekilde Şengül Bircan (2019) yaptığı çalışma ile formasyon programı öğrencilerinin öğretmenlik mesleğine ilişkin tutumlarının yüksek olduğunu tespit etmiş olması söz konusu araştırma bulgularını desteklemektedir.

Öğretmen adayları öğretmen olarak atandıklarında kişisel önceliklerini; kendini gerçekleştirmek, kişisel gelişimini sağlamak, etkili iletişim becerilerini kazanmak, eşitlik ve adalet, aileye destek, düzen, lider olmak, sorumluluk bilinci, sevgi ve saygı, maddi güç, saygınlık kazanmak ve yardımlaşma olarak sıralamışlardır. "Kendimi gerçekleştirmek" bulgusunun en çok rastlanan ifade olması dikkat çekici olmuştur. Öncelikli amaçları arasında kendini gerçekleştirmeye yer veren öğretmen adaylarının, kendini gerçekleştirme seviyesine ulaşana dek kişilik gelişimlerini sürekli hale getirecekleri, gelişim seviyesini bir üst düzeye çıkarmak için çaba gösterecekleri anlamını barındırmaktadır. Bu durum sonucunda da sürekli gelişim gösteren öğretmenlerin hem kendilerine hem de çevresindekilere özellikle öğrencilerine daha fazla yarar sağlayacakları öngörüsü yapılabilir.

Öğretmen adaylarının sosyal medya kullanımına ilişkin görüşleri incelendiğinde sosyal medyanın sıklıkla zaman çalıcı bir uygulama olduğunu belirttikleri görülmüştür. Bunun yanında olmazsa da olur diyerek sosyal medyayı önemsiz gören görüşlerin yanında olmazsa olmaz diyerek önemini dile getiren görüşler de yer almaktadır. Ayrıca sosyal medyanın amacına uygun kullanılırsa faydalı bir uygulama olacağını düşünen bazı öğretmen adayları ile sosyal medyayı iletişim aracı, eğlence, bilgiye ulaşma yolu, bağımlılık yaratan uygulama, gerçek dış1lı olarak belirtilen öğretmen adaylarının ifadelerine rastlanmıştır. Öğretmen adaylarının sosyal medya kullanımına yönelik olumlu tutum geliştirdikleri Ünsal ve Avar Vayvay (2018) ile Sağır ve Doğruluk (2018) tarafından yapılan çalışmalarla da tespit edilen bir sonuç olmuştur. Kınık ve diğerleri (2018) ise sosyal medya sitelerini kullanan öğretmen adaylarının, aile ve arkadaş çevresi ile iletişim halinde olmak, haberleri ve güncel olayları takip etmek ve vakitlerini değerli kılmak gibi sebeplerle sosyal medya sitelerindeki her adımı değerli gördüklerini tespit etmiştir. 
Sosyal medya kullanımının öğretmenlik mesleğine olumlu yanlarının ortaya çıkarılması hedeflenerek sorulan soruya verilen yanıtlar analiz edildiğinde öğretmen adayları sosyal medyayı; kendini güncellemek, bilgiye ulaşmak ve etkili iletişimin yolu olarak tanımlamışlardır. Yeşil ve Fidan (2017)'nin Y kuşağı üniversite öğrencileri üzerinde yaptıkları çalışmada bu öğrencilerin bilgiye ulaşma ve sorunları çözme de internet ve sosyal ağları önemli bir mecra olarak görüldükleri sonucu bu bulguyu destekler niteliktedir. Dönmez Usta ve Turan Güntepe (2018)'nin araştırma sonuçlarına göre öğretmen adaylarının büyük bir kısmının günde birkaç kez gündemi takip etmek, fotoğraf/video paylaşmak, dil geliştirmek amacıyla sosyal medyayı kullandığı belirlenmiştir. Bunun yanında gündemden haberdar olma, öğretim aracı, paylaşım yapılabilirliği ve ihtiyaç olduğu yönünde görüşlere de ulaşılmıştır. Bilgiye ulaşma ve sorunları çözmede internet önemli bir mecra olarak görülmektedir. Acun ve diğerlerinin (2018) üniversite öğrencileri üzerinde yaptığı çalışma sonuçları; sosyal medyanın kullanım örüntüleri bakımından dört önemli kullanım amacının olduğu yönündedir. Bu amaçlar vakit geçirme ve eğlence, siyasi konu ve gruplardan haberdar olma, araştırma, network kurma olarak sıralanmıştır. Başoğlu ve Yanar (2017) tarafından yapılan çalışmada benzer şekilde üniversite öğrencilerinin sosyal medyayı sıklıkla araştırma yapmak için kullandıkları rapor edilmiştir. Dönmez Usta ve Turan Güntepe (2018)'nin araştırmasında öğretmen adaylarının sosyal medyanın yeni bilgiler ve paylaşımlar yapma adına uygun olduğu, öğretim sürecinde sosyal medya kullanımının öğrenmeye katkı sağladığı, öğrenenin başarısını arttırdığına vurgu yapılmıştır.

Sosyal medya kullanımının öğretmenlik mesleğine olumsuz yanlarının ortaya çıkarılması hedeflenerek sorulan soruya verilen yanıtlar analiz edildiğinde öğretmen adayları sıklıkla zaman kaybı, amaçtan sapma, gerçek dışılık ve öğretmen hayatının deşifre olması yönünde görüş bildirmişlerdir. Ayrıca sosyal medyanın öğretmenleri tembelliğe alıştırması, asosyallik ve ahlaki çöküntüye neden olması, bağımlılık yaratması ve bilgi kirliliğine neden olmasını bakımından olumsuz olarak görülmüştür. Erdem ve diğerleri (2017)'ne göre öğretmen adayları sosyal medyayı etkin bir şekilde kullandıklarını belirtseler de aslında zararlı bir şey yaptıklarını düşünmekte ve ortaya koydukları metaforlarla da bu durumu dile getirmektedirler.

Araştırmadan çıkan sonuçlarla birlikte ortaya koyulabilecek en önemli yorum; beklentiyi karşılayacak şekilde eğitim sistemimizin en önemli paydaşlarından olan ve eğitim sisteminin etkililiğini doğrudan etkileyen, öğretmenlik mesleğini bilinçli ve etkili bir şekilde yerine getirmeye motive olmuş ve meslek hayatlarında da bu motivasyonla başlayacak öğretmen adaylarının varlığının umut verici olduğudur.

Hayatımızda çok fazla yer alan sosyal medyanın öğretmenler açısından hem olumlu hem de olumsuz yanları mevcuttur. Y kuşağı olarak adlandırılan öğretmen adaylarının sosyal medyanın olumlu taraflarını kullanması, olumsuz taraflarını ise meslek hayatının gerisinde tutması önerilebilir. Ayrıca sosyal medyayı kişisel ve mesleki önceliklerine uygun olarak kullanması başarılarını arttırıcı bir unsur olarak görülebilir.

\section{KAYNAKÇA}

Acun, İ., Yücel, C., Belenkuyu, C., \& Keleş, S. (2018). Üniversite öğrencilerinin sosyal medya kullanım amaçlarının incelenmesi. Kuram ve Uygulamada Eğitim Yönetimi Dergisi, 23(4), 559-602.

Akdemir, A., \& Konakay, G. (2014). Y kuşağının kariyer algısı, kariyer değişimi ve liderlik tarzı beklentilerinin araştırılması. Muğla Sitkı Koçman Üniversitesi İktisadi ve İdari Bilimler Fakültesi Ekonomi ve Yönetim Araştırmaları Dergisi, 2(2), 11-42

Aminul, İ., Cheong T. W., Yusuf H. \& Desa H. (2011). A study on generation at workplace in penang. Austrilian Journal of Basic and Applied Scinces, 1803-1806. 
Balcı, A. (2005). Sosyal bilimlerde araştırma. Ankara: Pegema Yayıncılık.

Başoğlu, U. D. \& Yanar, Ş. (2017). Üniversite öğrencilerinin sosyal medya kullanım amaçları ve alışkanlıklarının belirlenmesi. Kilis 7 Aralık Üniversitesi Beden Ë̆itimi ve Spor Bilimleri Dergisi, 1(2), 6-13.

Behrstock, E. \& Clifford, M. (2009). Leading gen y teachers: emerging strategies for school leaders. https://files.eric.ed.gov/fulltext/ED520777.pdf (09.09.2018 tarihinde erişilmiştir)

Bernard, H.R. (2002). Research methods in anthropology: Qualitative and quantitative methods. 3rd edition. AltaMira Press, Walnut Creek, California.

Cole F.L. (1988). Content analysis: process and application. ClinicalNurse Specialist, 2(1), 53-57.

Comte, A. (1974). The positive philosophy, (Ed. Abraham S. Blumberg). New York: AMS Pres.

Çakmak, M. \& Kayabaşı, Y. (2017). Öğretmen adaylarının öğretmenlik mesleğini seçme nedenlerinin çeşitli değişkenler açısından incelenmesi. Muğla Sıtkı Koçman Üniversitesi Eğitim Fakültesi Dergisi, 4(1), 1-10.

Dönmez Usta, N. \& Turan Güntepe E., (2018). Öğretmen adaylarının sosyal medya kullanım alışkanlıkları. Uluslararası Bilim ve Eğitim Kongresi.

Erdem, A., Alkan, M. F. \& Erdem, Ş. (2017). Öğretmen adaylarının sosyal medya kavramına ilişkin algıları. Karaelmas Ĕgitim Bilimleri Dergisi, 5(2).

Erlingsson, C. \& Brysiewicz, P. (2017). A hands-on guide to doing content analysis. African Journal of Emergency Medicine, 7(3), 93-99.

GAO (1996). Content Analysis a methodology for structuring andanalyzing written material. program evaluation and methodology division, United States General Accounting Office, Washington. https://www.gao.gov/assets/80/76281.pdf.

Islam, A., Cheong, T. W., Yusuf, D. H. M. \& Desa, H. (2011). A study on "Generation Y" behaviors at workplace in Penang. Journal of Applied Sciences Research, 7(11), 1802-1812.

İşçimen, D.S. (2012). Y Kuşağı çalışanlarının iş yaşamından beklentilerinin karşılanma düzeyiyle kurumsal bağlılık arasındaki ilişki ve bir örnek. Yayınlanmamış yüksek lisans tezi, Başakşehir Üniversitesi, İstanbul.

Kelgökmen İ. D. \& Yalçın, B. (2017). Y jenerasyonunun farklılaşan iş değerleri ve liderlik algılamaları. Journal of Yasar University, 12(46), 136-160

Kırnık, D., Pepeler, E. \& Özbek, R. (2018). Öğretmen adaylarının sosyal medya kullanımına ilişkin tutumlar1: Malatya il örneği. MANAS Sosyal Araştırmalar Dergisi, 7(1), 25-45.

Kupperschmidt, B. R. (2000), Multigeneration employees: strategies for effective management. The Health Care Manager, 19(1), 65- 76.

Lewis, J.L. \& S.R.J. Sheppard. (2006). Culture and communication: can landscape visualization improve forest management consultation with indigenous communities? Landscape and Urban Planning 77, 291-313.

McCrindle, M. \& Wolfinger, E. (2010). The ABC of XYZ: understanding the global generations. Australia: University of New South Wales Press.

Mengi, Z. (2009). Z kuşağ1 geliyor. (http://www.zeynepmengi.com/2012/06/z-kusagi-geliyor/) Erişim Tarihi: 05.01.2018. 
Miles, M.B. \& Huberman, A.M. (1994). Qualitative data analysis. Thousand Oaks, CA: Sage.

Patalano, C. (2008). A study of the relationship between generational group identification and organizational commitment: generation X vs. generation Y, Unpublished Doctoral Thesis. H. Wayne Huizengo School of Business \& Entrepreneurship Nova Southeastern University.

Reilly, P. (2012). Understanding and teaching generation $Y$. https://americanenglish.state.gov/files/ae/resource_files/reilly_understanding_and_teaching_g eneration_y.p (09.09.2018 tarihinde erişilmiştir).

Sağır, M. \& Doğruluk, S. (2018). Öğretmen adaylarının sosyal medyaya ilişkin tutumları ile internet bağımlılıkları arasındaki ilişki. Abant İzzet Baysal Üniversitesi Eğitim Fakültesi Dergisi, 18(2), 1041-1063.

Stone P. J., Dunphy D. C., Marshall S. S. \& Ogilvie, D.M. (1966) The general inquirer: A computer approach to content analysis. The M.I.T. Press, Massachusetts.

Şengül Bircan, T. (2019). Pedagojik formasyon eğitimi alan tarih öğretmen adaylarının öğretmenlik mesleğine ilişkin tutumlar1. Kastamonu Eğitim Dergisi, 27(2), 589-598.

Thornton, A. \& Young-DeMarco, L. (2001). Four decades of trends in attitudes toward family issues in the United States: The 1960s through the 1990s. Journal of Marriage and the Family, 63, 10091037.

Tongco MDC. (2007). Purposive sampling as a tool for informant selection. Ethnobotany Research \& Applications 5:147-158.

Trzesniewski, K., Donnellan, M.B. \& Robins, R. (2008). Is "generation me" really more narcissistic than previous generations?. Journal of Personality 76(4), 903-918.

Twenge, J. M., Campbell, S. M., Hoffman, B. J., \& Lance, C. E. (2010). Generational differences in workvalues: Leisure and extrinsic value sincreasing, social and intrinsic values decreasing. Journal of Management,36(5), 1117-1142.

Twenge, J. M., Zhang, L., \& Im, C. (2004). It's beyond my control: A cross- temporal meta-analysis of increasing externality in Locus of Control, 1960- 2002. Personality and Social Psychology Review, 8, 308-319.

Ünsal, S. \& Avar Vayvay, N. (2018). Öğretmen adaylarının sosyal medya kullanımlarıyla e-öğrenmeye yönelik tutumları arasındaki ilişkinin incelenmesi, Route Educational and Social Science Journal, 5(5), 25-40.

Wells, B. E. \& Twenge, J. M. (2005). Changes in young people's sexual behavior and attitudes, 19431999: A cross-temporal meta-analysis. Review of General Psychology, 9 , 249-261.

Williamson, R. \& Meyer-Looze, C. (2010). Working with Gen Y Teachers: Dealing with a Changing Teacher Workforce. Education Partnerships, Inc.

Yaşa, E. \& Bozyiğit, S. (2012). Y Kuşağı tüketicilerinin cep telefonu ve gsm operatörleri tercihi: mersin ilindeki üniversite öğrencilerinin tercihlerini belirlemeye yönelik pilot bir araştırma. Çă̆ Üniversitesi Sosyal Bilimler Dergisi, 9(1).

Yeşil, Y. \& Fidan, F. (2017). Türkiye'de Y Kuşağının e-iletişim kullanımı: üniversite öğrencileri üzerinde bir araştırma. Balkan ve Yakın Doğu Sosyal Bilimler Dergisi, 3(1). 100-109

Yıldırım, A. \& Şimşek, H. (2005). Sosyal bilimlerde nitel araştırma yöntemleri. Ankara: Seçkin Yayınevi. 